OPEN ACCESS

Edited by:

Caoxing Huang,

Nanjing Forestry University, China

Reviewed by:

Minmeng Zhao,

Yangzhou University, China

Wenhui Geng,

North Carolina State University,

United States

${ }^{*}$ Correspondence:

Bolin Zhang

zhangbolin@zync.edu.cn

Zewei Sun

sunzewei@jlau.edu.cn

Specialty section:

This article was submitted to

Industrial Biotechnology,

a section of the journal

Frontiers in Bioengineering and

Biotechnology

Received: 19 November 2020 Accepted: 23 December 2020 Published: 10 February 2021

Citation:

Zhang B, Liu N, He Z, Song P. Hao M, Xie Y, Li J, Liu R and Sun Z (2021) Guanidino-Acetic Acid:

A Scarce Substance in Biomass That Can Regulate Postmortem Meat Glycolysis of Broilers Subjected to Pre-slaughter Transportation. Front. Bioeng. Biotechnol. 8:631194. doi: 10.3389/fbioe.2020.631194

\section{Guanidino-Acetic Acid: A Scarce Substance in Biomass That Can Regulate Postmortem Meat Glycolysis of Broilers Subjected to Pre-slaughter Transportation}

Bolin Zhang ${ }^{1 *}$, Ning Liu ${ }^{1}$, Zhen He ${ }^{1}$, Peiyong Song ${ }^{1}$, Meilin Hao ${ }^{1}$, Yuxiao Xie ${ }^{1}$, Jiahui Li , Rujie Liu ${ }^{1}$ and Zewei Sun ${ }^{2 *}$

'Department of Biology and Agriculture, Characteristic Laboratory of Animal Resources Conservation and Utilization of Chishui River Basin, Zunyi Normal College, Zunyi, China, ${ }^{2}$ College of Animal Science and Technology, Jilin Agricultural University, Changchun, China

The different substances in biomass can regulate the metabolism and reproduction of broilers. Guanidino-acetic acid (GAA) is a natural feed additive that showed a potential application in dietary for broilers, while its amount is scarce in biomass. The objective of the present study was to investigate the effects of dietary supplemented with GAA on muscle glycolysis of broilers subjected to pre-slaughter transportation. A total of 160 Qiandongnan Xiaoxiang chickens were randomly assigned into three treatments, including a basal control diet without GAA supplementation (80 birds) or supplemented with $600 \mathrm{mg} / \mathrm{kg}$ (40 birds) or 1,200 mg/kg (40 birds) GAA for 14 days. At the end of the experiment, the control group was equally divided into two groups, thus resulting in four groups. All birds in the four groups aforementioned were separately treated according to the following protocols: (1) no transport of birds of the control group fed with the basal diet; (2) a 3-h transport of birds of the control group fed with the basal diet; (3) a 3-h transport of birds fed with diets supplemented with $600 \mathrm{mg} / \mathrm{kg} \mathrm{GAA}$; and (4) a 3-h transport of birds fed with diets supplemented with 1,200 mg/kg GAA. The results demonstrated that 3-h pre-slaughter transport stress increased corticosterone contents and lowered glucose contents in plasma $(P<0.05)$, decreased $\mathrm{pH}_{24 \mathrm{~h}}(P<0.05)$, and resulted in inferior meat quality evidenced by elevating the drip loss, cooking loss, and $L^{*}$ value $(P<0.05)$. Meanwhile, 3 -h pre-slaughter transport stress decreased the contents of $\mathrm{Cr}$ and ATP in muscle $(P<0.05)$ and elevated the ratio of AMP:ATP and the glycolytic potential of muscle $(P<0.05)$. Moreover, 3-h pre-slaughter transport resulted in a significant elevation of mRNA expressions of LKB1 and AMPK $\alpha 2(P<0.05)$, as well as the increase in protein abundances of LKB1 phosphorylation and AMPK $\alpha$ phosphorylation $(P<0.05)$. However, 1,200 mg/kg GAA supplementation alleviated negative parameters in plasma, improved meat quality, and ameliorated postmortem glycolysis and energy metabolism through regulating the creatine-phosphocreatine 
cycle and key factors of AMPK signaling. In conclusion, dietary supplementation with $1,200 \mathrm{mg} / \mathrm{kg}$ GAA contributed to improving meat quality via ameliorating muscle energy expenditure and delaying anaerobic glycolysis of broilers subjected to the 3-h pre-slaughter transport.

Keywords: guandino-acetic acid, transport stress, postmortem glycolysis, AMPK signaling, broiler

\section{INTRODUCTION}

Pale, soft, and exudative (PSE)-like meat, characterized by lighter appearance, softer texture, lower water holding capacity, excessive yield losses, and formation of soft gels, has been recognized for decades and causes huge economic losses annually for modern poultry industry due to its inferior quality (Desai et al., 2016; Wang et al., 2017). In previous studies, it has been suggested that a 3 -h pre-slaughter transport resulted in a significant decrease of glucose concentration in plasma and a sharp increase in plasma corticosterone level (Zhang et al., 2014, 2017), which are the two most sensitive indicators of transport stress. Moreover, pre-slaughter transportation accelerated energy consumption in muscle of broilers and resulted in a stressinduced increase in glycolysis, further inducing the accumulation of lactic acid in muscle (Hambrecht et al., 2005; Zhang et al., 2009). It has been well established that fast and excessive glycolysis, a rapid accumulation of lactic acid, and high temperature in muscle of early postmortem are the causes of PSE-like syndrome (Li et al., 2016). Therefore, pre-slaughter transport was considered to be one of the most important factors contributing to an increase in incidences of PSE-like chicken meat (Huang et al., 2018). Moreover, Xing et al. (2016) demonstrated that pre-slaughter transport induced a lower energy status in the early postmortem period, followed by an elevation of the concentration of lactic acid and an inferior meat quality. As a result, pre-slaughter transportation is one of the most important pre-harvest variables related to meat quality and should be regarded as a critical control point (Speer et al., 2001; Schwartzkopf-Genswein et al., 2012). Therefore, it is necessary to take a nutritional strategy to improve energy storage and alleviate the adverse effects of pre-slaughter transportation on meat quality of broilers.

Creatine $(\mathrm{Cr})$ is heavily involved in energy metabolism through the $\mathrm{Cr}$ and phosphocreatine system, an important cellular energy source for rapid regeneration of ATP to meet the increased energy demands of intense activities of tissues, particularly muscle cells (Michiels et al., 2012; Zhang et al., 2017). It has been demonstrated that $\mathrm{Cr}$, a natural regulator of energy homeostasis, could buffer energy concentration in tissues with significant and fluctuating energy demands, especially in muscles and brains (Ostojic et al., 2013). Guanidino-acetic acid (GAA) is the only immediate precursor of $\mathrm{Cr}$ in the body and is a naturally occurring compound in vertebrate animals (Dilger et al., 2013). Importantly, GAA is more chemically stable and more effective than $\mathrm{Cr}$ at enhancing tissue $\mathrm{Cr}$ storage (McBreairty et al., 2015). Accordingly, GAA was considered to be more suitable than $\mathrm{Cr}$ as a new natural feed additive. It has been demonstrated that dietary supplemented with GAA increased the contents of $\mathrm{Cr}$ and phosphorus creatine (PCr) in muscle and improved the state of energy metabolism (Degroot, 2015). A previous study demonstrated that the increased concentrations of $\mathrm{Cr}$ and $\mathrm{PCr}$ and the higher ratio of $\mathrm{PCr}$ : $\mathrm{Cr}$ were observed by GAA supplemented in the diet (Liu et al., 2015). In addition to being involved in the regulation of energy metabolism, GAA also played an important role in improving meat quality. It has been reported that GAA supplementation increased postmortem muscle $\mathrm{pH}$, lowered drip loss and cooking loss, and significantly reduced the shear force of meat (Wang et al., 2012). This may be due to the fact that dietary GAA supplementation increased available energy reserve such as PCr and ATP, which contributes to delaying the energy release of glycolysis and the accumulation of lactic acid, and consequently maintained a $\mathrm{pH}$ value postmortem. Moreover, Liu et al. (2015) suggested that GAA supplementation significantly decreased the activity of hexokinase, the rate-limiting enzyme in glycolysis, which means that GAA regulated the process of muscle energy metabolism through postmortem muscle glycolysis. However, the regulation mechanisms of GAA on postmortem glycolysis are still unknown.

Adenosine 5'-monophosphate (AMP)-activated protein kinase (AMPK), the downstream component of the protein kinase signal cascade pathway, is a key factor in sensing intracellular energy status and acts as a crucial component in regulating energy balance at both the cellular and whole body levels (Hardie, 2011). AMPK is an important energy sensor in the body, which is called the "energy regulator" of eukaryotic cells. AMPK was activated in response to stresses such as the exhaustion of ATP and the increase of the proportion of ADP/ATP, consequently accelerating postmortem glycolysis (Graeme and Hardie, 2014). Besides, postmortem glycolysis was inhibited in AMPK knockout mice, suggesting that APMK could be a target to control postmortem glycolysis (Shen et al., 2008). Thus, we hypothesized that GAA regulated the postmortem glycolysis through the AMPK signaling pathway. Therefore, the objective of our study was to evaluate the effects of GAA supplementation on meat quality and intracellular energy metabolism of muscle, further determining the activities of key enzymes involved in glycolysis and gene or protein expressions of important components in the AMPK signaling pathway of broilers subjected to pre-slaughter transport.

\section{MATERIALS AND METHODS}

\section{Animal Care, Diet, and Management}

All the procedures including animal care and experiment treatments were in accordance with guidelines approved by the Institutional Animal Care and Use Committee of Zunyi Normal College. The basal diet was formulated to meet the nutrient requirements of Nutrient Requirements of Chinese Meat-Type 
Yellow Feathered Chickens. The composition and nutritional level of the diet are as shown in Table $\mathbf{1 .}$

One hundred and sixty Qiandongnan Xiaoxiang chickens (purchased from Guizhou Rongjiang Shannong Development Co., Ltd., China) 22 weeks old were randomly assigned into three treatments, including a basal control diet without GAA supplementation ( 80 birds) or supplemented with $600 \mathrm{mg} / \mathrm{kg}$ (40 birds) or $1,200 \mathrm{mg} / \mathrm{kg}$ (40 birds) GAA for 14 days. The source of GAA additive (>99\% purity) was from Tianjin Tiancheng Pharmaceutical Co., Ltd. (Tianjin, China). Each treatment was consisted of 20 replicates and two broilers per cage, but the control group had 40 replicates and two broilers per cage. All birds were housed in an environmentally controlled facility and were ad libitum access to the feed in mash form and fresh water. At the end of the experiment, the body weight of the bird as the unit of pen was weighted after an 8-h feed deprivation. Average daily weight gain (ADG) and feed intake (ADFI) were calculated.

\section{Transportation and Sample Collection}

Before transportation treatment, all birds were tagged and fasted overnight without water withdrawal. The control group was averagely divided into two groups, thus resulting in four groups consisting of two control groups and two GAA supplementation groups. All birds in the four groups mentioned above were transported from the rearing house to the slaughterhouse according to the following protocols: (1) no transport of birds of the control group fed with the basal diet; (2) a 3-h transport of birds of the control group fed with the basal diet; (3) a 3-h transport of birds fed with diets supplemented with $600 \mathrm{mg} / \mathrm{kg}$ GAA; and (4) a 3-h transport of birds fed with diets supplemented with $1,200 \mathrm{mg} / \mathrm{kg}$ GAA.

No water or feed was provided during the transportation period. The transportation distance is about $240 \mathrm{~km}$ with an average speed of $80 \mathrm{~km} / \mathrm{h}$. After a 3-h transportation and rest for $1 \mathrm{~h}, 10$ broilers with a body weight close to the mean body weight in each group were randomly selected for blood sampling. Blood samples were collected into 10-mL Eppendorf tubes coated with EDTA via wing vein puncture to collect plasma for subsequent analysis.

The left pectoralis major (PM) was taken from broilers within 10 min after slaughter and stored at $4^{\circ} \mathrm{C}$ for meat quality analysis. In addition, about $5 \mathrm{~g}$ of right PM was collected into the frozen tube and stored in liquid nitrogen for further analysis.

\section{Growth Performance}

At the beginning and end of the experiment, the body weights of broilers were separately recorded per pen. Feed consumption was recorded daily. Thus, the ADG, ADFI, and ratio of feed intake to the average daily weight gain $(F: G)$ were calculated for each replicate pen of chicken.

\section{Concentrations of Glucose and Corticosterone in Plasma}

The concentration of glucose was analyzed using commercial test kits (Nanjing Jiancheng Bioengineering Institute, Nanjing, China) according to the protocols of manufacture. The concentration of corticosterone was determined with commercial kits (Cusbio Biotech. Co., Ltd., Wuhan, China).

\section{Meat Quality}

Postmortem $\mathrm{pH}$ at $45 \mathrm{~min}\left(\mathrm{pH}_{45 \mathrm{~min}}\right)$ of the left $\mathrm{PM}$ were measured with PHBF-260 portable $\mathrm{pH}$ meter (Shanghai Instrument Electric Science Instrument Co., Ltd., Shanghai, China) and then were stored at $4^{\circ} \mathrm{C}$ to determine postmortem $\mathrm{pH}$ at $24 \mathrm{~h}\left(\mathrm{pH}_{24 \mathrm{~h}}\right)$. Each sample was measured at 3 locations. The probe of the $\mathrm{pH}$ meter was inserted into $\mathrm{PM}$ at an angle of $45^{\circ}$ and was washed using ultrapure water between different samples. The values of meat color including $\mathrm{a}^{*}$ (redness), $\mathrm{b}^{*}$ (yellowness), and $\mathrm{L}^{*}$ (lightness) at postmortem $24 \mathrm{~h}$ of the right PM were determined using a YS3010 portable spectrophotometer (Shenzhen San'enshi Technology Co., Ltd., Shenzhen, China). Drip loss, cooking loss, and shear force of PM were measured according to the protocols reported by the previous studies (Yue et al., 2010; Zhang et al., 2019).

\section{Concentration of $\mathrm{Cr}, \mathrm{PCr}$, and Adenosine Nucleotides in Muscle}

The concentrations of Cr, PCr, ATP, ADP, and AMP in muscle were determined by HPLC as previously reported with moderately modified (Wang et al., 2017; Zhang et al., 2017). Three hundred milligram frozen muscle samples were collected into tubes containing ice-cold perchloric acid and were homogenized for $1 \mathrm{~min}$, followed by standing in an ice bath for $15 \mathrm{~min}$. Then, the homogenates were centrifuged at $15,000 \mathrm{~g}$ at $4^{\circ} \mathrm{C}$ for $10 \mathrm{~min}$ to collect supernatants and further filtered through a $0.45-\mu \mathrm{m}$ membrane. A $10-\mu \mathrm{L}$ volume of each sample was injected into an Alliance HPLC system (Alliance HPLC system 2695, Water Corporation, Milford, MA, United States) equipped with a Waters SunFire C18 column $(250 \mathrm{~mm} \times 4.6 \mathrm{~mm}$, $5 \mu \mathrm{m}$ ) at a temperature of $25^{\circ} \mathrm{C}$ for $\mathrm{Cr}$ and $\mathrm{PCr}$ determination, and at a temperature of $30^{\circ} \mathrm{C}$ for ATP, ADP, and AMP analysis. The ultraviolet wavelength for $\mathrm{Cr}$ and $\mathrm{PCr}$ determination and the analysis of ATP, ADP, and AMP were 210 and $245 \mathrm{~nm}$, respectively. The mobile phase was a mixture of methyl cyanides and $29.4 \mathrm{mM} \mathrm{KH} \mathrm{KO}_{4}$ buffer (2:98, volume ratio) for $\mathrm{Cr}$ and $\mathrm{PCr}$ determination and was a mixture of methanol and phosphate buffer (13.5:86.5, volume ratio) for ATP, ADP, and AMP analysis, and the flow rate was $1 \mathrm{~mL} / \mathrm{min}$. The standards of creatine and phosphocreatine disodium salt, and $5^{\prime}$-ATP disodium salt, $5^{\prime}$-ADP sodium salt, and $5^{\prime}$-AMP sodium salt were all purchased from Sigma-Aldrich, Inc. (Sigma-Aldrich Inc., St. Louis, MO, United States).

\section{Analysis of Activities of Glycolytic Key Enzymes}

The activities of glycolytic key enzymes, including hexokinase $(\mathrm{HK})$, pyruvate kinase (PK), and phosphofructokinase (PFK), were conducted with commercial kits (Nanjing Jiancheng Bioengineering Institute, Nanjing, China). All operation protocols were according to instructions of manufacture. 


\section{Determination of Glycogen, Lactic Acid, and Glycolytic Potential in Muscle}

About $0.50 \mathrm{~g}$ (weighed exactly) frozen muscle sample was homogenized for $1 \mathrm{~min}$ in $4.5 \mathrm{~mL}$ ice-cold saline then was centrifuged for $10 \mathrm{~min}$ at $4,000 \mathrm{rpm}$ at $4^{\circ} \mathrm{C}$ to collect superannuants for determining the concentration of lactic acid in muscle with a standard commercial kit (Nanjing Jiancheng Bioengineering Institute, Nanjing, China). Glycogen content was measured as previously reported (Zhang et al., 2009). Both lactic acid and glycogen contents were used to calculate the glycolytic potential (GP) according to the formula: $\mathrm{GP}=2 \times$ [glycogen] + [lactic acid], which was expressed as $\mu \mathrm{mol}$ of lactic acid equivalent per gram of wet muscle (Monin and Sellier, 1985).

\section{RNA Extraction and Real-Time PCR Analysis}

The mRNA expressions of the selected genes were evaluated by real-time PCR. Total RNA from muscle samples were extracted using RNAiso Plus reagent (catalog no. 9108, TaKaRa Biotechnology (Dalian) Co., Ltd., Dalian, China) according to the manufacturer's protocols. The purity of the total RNA was quantified by evaluating the OD260/OD280 ratio with a ND1000 spectrophotometer (NanoDrop, Thermo Fisher Scientific). Samples with $260 / 280$ ratios of 1.8 - Ito 2.0 and $260 / 230$ ratios of 2.0 to 2.2 were used for PCR reactions. Reverse transcription was conducted with the PrimeScript ${ }^{\mathrm{TM}}$ RT Master Mix (catalog no. RR037A, TaKaRa), and real-time RT-PCR was conducted using TB Green Premix Ex Taq (catalog no. RR420A). The PCR program was as follows: one cycle at $95^{\circ} \mathrm{C}$ for $30 \mathrm{~s}$ and 40 cycles at $95^{\circ} \mathrm{C}$ for $5 \mathrm{~s}$, followed by $60^{\circ} \mathrm{C}$ for $30 \mathrm{~s}$. The expression of target genes relative to the housekeeping gene ( $\beta$-actin) was analyzed according to the method by Livak and Schmittgen (2000). All samples were processed in triplicate. The relative mRNA expression of each target gene was normalized to the control group (no transportation stress). The primer sequences for the target and housekeeping genes are shown in Table 2.

\section{Western Blot}

Approximately $10 \mathrm{mg}$ frozen muscle samples was homogenized in tubes with $200 \mu \mathrm{L}$ lysis buffer, then was centrifuged for $10 \mathrm{~min}$ at $12,000 \mathrm{rpm}$ and $4^{\circ} \mathrm{C}$ to collect the supernatant, followed by protein quantification assay. Each muscle supernatant was mixed with an equal amount of $2 \times$ standard SDS sample loading buffer containing $0.5 \mathrm{M}$ Tris- $\mathrm{HCl}(\mathrm{pH}$ 6.8), $4.4 \%$ $(\mathrm{w} / \mathrm{v})$ SDS, $20 \%(\mathrm{v} / \mathrm{v})$ glycerol, $2 \%(\mathrm{v} / \mathrm{v}) 2$-mercaptoethanol, and $0.01 \%$ bromophenol blue and was boiled at $100^{\circ} \mathrm{C}$ for $5 \mathrm{~min}$ before electrophoresis. The extracted protein samples with equal amount $(30 \mu \mathrm{g} / \mathrm{lane})$ were loaded onto $10 \%$ sodium dodecyl sulfate polyacrylamide gel and transferred to a polyvinylidene difluoride membrane (Millipore, Billerica, MA, United States). Membrane blocking was conducted with $5 \%$ bovine serum albumin for $1 \mathrm{~h}$ and was incubated with primary antibodies $(1: 1,000)$ overnight at $4^{\circ} \mathrm{C}$ with gentle shaking. The membranes were washed three times with TBST $(1 \times$ Tris buffered saline
TABLE 1 | Composition and nutrient levels of the basal diet (air-dry basis,\%).

\begin{tabular}{lrlc}
\hline Items & Contents & Nutrient levels & Contents \\
\hline Corn & 68.50 & ${ }^{2}$ Crude protein (\%) & 16.00 \\
Soybean meal & 12.00 & Metabolic energy (MJ/kg) & 13.03 \\
Corn gluten meal & 3.60 & Lysine (\%) & 0.85 \\
Rapeseed meal & 1.95 & Methionine (\%) & 0.65 \\
Soybean oil & 3.93 & Calcuim (\%) & 0.81 \\
L-Lysine HCl & 0.32 & Available phosphorus (\%) & 0.35 \\
DL-Methionine & 0.10 & & \\
Calcuim monophosphate & 1.30 & & \\
Limestone & 0.85 & & \\
Salt & 0.30 & & \\
$1 \%$ Premix & 1.00 & & \\
\hline
\end{tabular}

${ }^{1}$ Premix provided the following per $\mathrm{kg}$ of the diet: vitamin A 10,000 $\mathrm{U}$; vitamin D3 2,000 IU; vitamin E $25 \mathrm{mg}$; Vitamin K, $2.8 \mathrm{mg}$; thiamine $2.50 \mathrm{mg}$; riboflavin $7.5 \mathrm{mg}$; nicotinamide $40 \mathrm{mg}$; calcium pantothenate, $25 \mathrm{mg}$; pyidoxine. $\mathrm{HCl}, 3 \mathrm{mg}$; biotin, $0.20 \mathrm{mg}$; folic acid, $1.5 \mathrm{mg}$; vitamin B12, $0.015 \mathrm{mg}$; ferrous (as ferrous sulfate) $80 \mathrm{mg}$; copper (as copper sulfate) $8 \mathrm{mg}$; manganese (as manganese sulfate) $100 \mathrm{mg}$; zinc (as zinc sulfate) $60 \mathrm{mg}$; iodine (as potassium iodide) $0.35 \mathrm{mg}$; selenium (as sodium selenite) $0.3 \mathrm{mg}$.

${ }^{2}$ Nutrient content of the diets were the value of measurement.

including $0.1 \%$ Tween 20 ) and then were incubated with a second antibody of horseradish peroxidase-conjugated (1:3,000, Cell Signaling Technology Inc., Beverly, MA, United States) at room temperature. The primary antibodies for phorsphorLKB1 (Thr189, no. 3054s, 1:1,000), phorsphor-AMKP $\alpha$ (Thr172, no. 2531s, 1:1,000), and $\alpha$-Tubulin (no. 2125s, 1:1,000) were purchased from Cell Signaling Technology Inc. (Beverly, MA, United States) and were validated previously for use with chicken samples (Zhang et al., 2017). The membranes were developed using ECL chemiluminescent reagents (Tanon Science and Technology Co., Ltd., Shanghai, China) and exposed to Kodak film. Band densities were quantified using Scion Image software (Scion Corporation, Frederick, MD, United States) and were normalized to $\alpha$-tubulin and expressed as the relative values to those for the control group.

\section{Statistical Analysis}

All data were statistically analyzed with the SAS program (version 8.02, SAS Institute Inc., Cary, NC, United States). All data were normally distributed and were analyzed using analysis of one-way analysis of variance. Significant differences among treatment means were analyzed by Duncan's multiple-range test. The results were presented with mean values with their standard deviation, and a $P$ value of less than 0.05 was considered statistically significant.

\section{RESULTS}

\section{Growth Performance}

The results of dietary supplemented with GAA on growth performance of Qiangdongnan Xiaoxiang chickens are shown in Table 3. Both $600 \mathrm{mg} / \mathrm{kg}$ GAA and $1,200 \mathrm{mg} / \mathrm{kg}$ GAA supplementation in diets did not affect $A D G, A D F I$, or $F / G$ when compared with those fed with the control diet $(P>0.05)$. 
TABLE 2 | Sequences used for real-time PCR primers.

\begin{tabular}{|c|c|c|c|}
\hline Genes & Primers $\left(5^{\prime} \rightarrow 3^{\prime}\right)$ & Product size (bp) & Gene Bank ${ }^{1}$ \\
\hline \multirow[t]{2}{*}{$L K B 1$} & Sense: GTATGACGGCGGTGCCTTATCTG & 121 & NM_001045833.1 \\
\hline & Antisense: ACCTGTCCTGGTACTGTGAAGTCC & & \\
\hline \multirow[t]{2}{*}{$A M P K \alpha 1$} & Sense: TGTGTATGTGCAGCAACCCG & 195 & NM_001039603.1 \\
\hline & Antisense: AACAACCAGCTATGCACCCC & & \\
\hline \multirow[t]{2}{*}{$A M P K \alpha 2$} & Sense: TCATCAGCACGCCAACAGACTTC & 106 & NM_001039605.1 \\
\hline & Antisense: CGAGCCTCTGCСTCTTCAACAC & & \\
\hline \multirow[t]{2}{*}{$\beta$-actin } & Sense: ATTGTCCACCGCAAATGCTTC & 113 & NM_205518.1 \\
\hline & Antisense:AAATAAAGCCATGCCAATCTCGTC & & \\
\hline
\end{tabular}

LKB1, liver kinase B1; AMPKa1, adenosine 5'-monophosphate-activated protein kinase $\alpha 1$; AMPK $\alpha 2$, adenosine 5'-monophosphate-activated protein kinase $\alpha 2$. ${ }^{1}$ Genbank Accession Number.

TABLE 3 | Effect of dietary supplemented with GAA on growth performance of Qiandongnan Xiaoxiang Chicken.

\begin{tabular}{|c|c|c|c|c|}
\hline Items & Control group & 600 mg/kg GAA group & $1,200 \mathrm{mg} / \mathrm{kg}$ GAA group & $P$ value \\
\hline ADG (g) & $24.60 \pm 1.34$ & $25.09 \pm 3.44$ & $23.86 \pm 3.77$ & 0.850 \\
\hline $\operatorname{ADFI}(\mathrm{g})$ & $110.0 \pm 4.43$ & $105.8 \pm 3.98$ & $108.1 \pm 4.80$ & 0.426 \\
\hline $\mathrm{F} / \mathrm{G}(\mathrm{g} / \mathrm{g})$ & $4.49 \pm 0.36$ & $4.27 \pm 0.57$ & $4.65 \pm 1.02$ & 0.754 \\
\hline
\end{tabular}

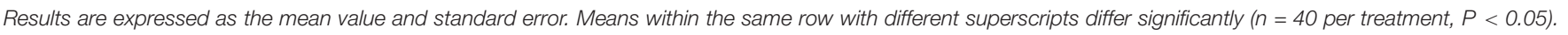

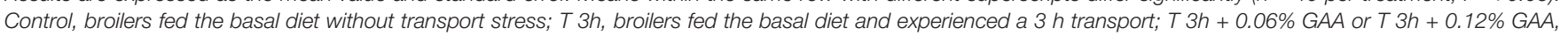

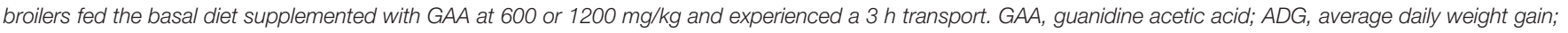
$A D F I$, average daily feed intake; F/G, the ratio of feed to gain.

Similarly, there were no differences in ADG, ADFI, or F/G between $600 \mathrm{mg} / \mathrm{kg} \mathrm{GAA}$ and $1,200 \mathrm{mg} / \mathrm{kg}$ GAA supplementation group $(P>0.05)$.

\section{Plasma Parameters}

The concentrations of glucose and corticosterone in plasma are shown in Figure 1. Compared with those in the control group (no pre-slaughter transport stress), the 3-h pre-slaughter transport significantly decreased the concentration of glucose and elevated the contents of corticosterone in plasma $(P<0.05$, Figures 1A,B). However, dietary supplemented with 1,200 mg/kg GAA decreased the concentration of corticosterone of broilers induced by the 3 -h pre-slaughter transport $(P<0.05)$. Moreover, there was no difference in the concentration of glucose or corticosterone between the control group and the $1,200-\mathrm{mg} / \mathrm{kg}$ GAA supplementation group $(P>0.05)$.

\section{Meat Quality}

As shown in Table 4, compared with broilers without transport stress, $\mathrm{pH}_{24 \mathrm{~h}}$ values of broilers subjected to 3 - $\mathrm{h}$ transport stress were significantly decreased $(P<0.05)$. In contrast, the drip loss, cooking loss, and $\mathrm{L}^{*}$ value were all increased by 3 -h transport stress $(P<0.05)$. However, the values of $\mathrm{pH}_{45 \mathrm{~min}}, \mathrm{a}^{*}, \mathrm{~b}^{*}$, and shear force were not affected $(P>0.05)$. Diets supplemented with $600 \mathrm{mg} / \mathrm{kg}$ GAA or $1,200 \mathrm{mg} / \mathrm{kg}$ GAA similarly resulted in a higher value of $\mathrm{pH}_{24 \mathrm{~h}}$ and the lower drip loss and $\mathrm{L}^{*}$ of broilers in comparison with those subjected to 3-h transport stress $(P<0.05)$. Besides, compared with $3-\mathrm{h}$ transport stress, the cooking loss was lowered by $1200 \mathrm{mg} / \mathrm{kg}$ GAA supplementation $(P<0.05)$. However, both $600 \mathrm{mg} / \mathrm{kg}$ GAA and $1,200 \mathrm{mg} / \mathrm{kg}$ GAA supplemented did not affect the values of $\mathrm{pH}_{45 \mathrm{~min}}, \mathrm{a}^{*}$, and $b^{*}(P>0.05)$. Moreover, the drip loss of broilers fed with $1,200 \mathrm{mg} / \mathrm{kg}$ GAA was significantly lower than those fed with
$600 \mathrm{mg} / \mathrm{kg}$ GAA diet $(P<0.05)$. No differences in parameters of meat quality measured in our study were observed between the $1,200-\mathrm{mg} / \mathrm{kg}$ GAA supplementation group and the control group $(P>0.05)$.

\section{Concentrations of $\mathrm{Cr}, \mathrm{PCr}$, ATP, ADP, and AMP in Muscle}

As shown in Table 5, compared with the control group, 3$\mathrm{h}$ transport stress significantly decreased the contents of $\mathrm{Cr}$ and ATP in PM $(P<0.05)$ but elevated the contents of ADP, AMP, and the ratio of AMP: ATP $(P<0.05)$. However, no differences in the ratio of $\mathrm{PCr}: \mathrm{Cr}$ and the concentration of $\mathrm{PCr}$ between 3-h transport stress and the control group were observed $(P>0.05)$. Compared with the 3 -h pre-slaughter transport treatment, dietary supplemented with $600 \mathrm{mg}$ GAA significantly increased the contents of $\mathrm{Cr}$ and $\mathrm{PCr}$ in $\mathrm{PM}(P<0.05)$. However, the contents of ATP, ADP, and AMP and the ratio of PCr:Cr and AMP:ATP $(P>0.05)$ were not affected by dietary supplemented with $600 \mathrm{mg}$ GAA when compared with 3-h transport stress. Notably, compared with 3-h pre-transport stress, dietary supplemented with 1,200 mg GAA exhibited significant increases in the contents of $\mathrm{Cr}, \mathrm{PCr}$, and ATP in muscle $(P<0.05)$. Furthermore, the contents of ADP and AMP and the ratio of AMP:ATP $(P<0.05)$ by $1,200 \mathrm{mg}$ GAA supplementation were lower than those of 3-h transport stress. However, there were no differences in the ratio of $\mathrm{PCr}$ : $\mathrm{Cr}$ among four treatments $(P>0.05)$.

\section{Glycolytic Potential of Pectoralis Major Muscle}

The results of the glycolytic potential of PM muscle of Qiandongnan Xiaoxiang chickens fed with GAA are shown 

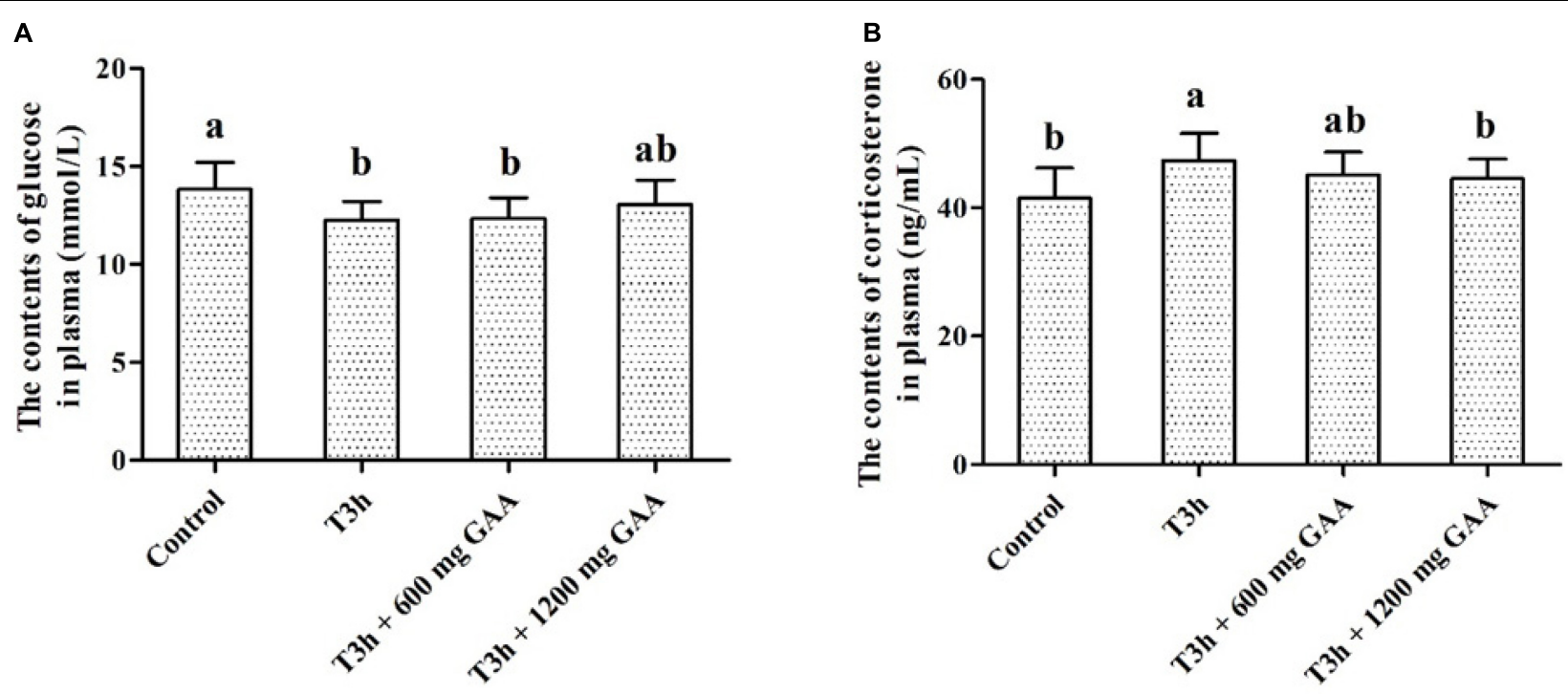

FIGURE 1 | Effects of dietary GAA supplementation on the contents of glycose (A) and corticosterone (B) plasma of Qiandongnan Xiaoxiang Chicken experienced transport stress ( $n=10$ per treatment). Results are expressed as the mean value and standard error. Means within the same row with different superscripts differ significantly $(n=10$ per treatment, $P<0.05)$. Control, broilers fed the basal diet without transport stress; T3h, broilers fed the basal diet and experienced a $3 \mathrm{~h}$ transport; T $3 \mathrm{~h}+0.06 \%$ GAA or T $3 \mathrm{~h}+0.12 \%$ GAA, broilers fed the basal diet supplemented with GAA at 600 or $1,200 \mathrm{mg} / \mathrm{kg}$ and experienced a $3 \mathrm{~h}$ transport. GAA, guanidine acetic acid.

TABLE 4 | Effects of dietary supplementation with GAA on meat quality of the pectoralis major muscle of Qiandongnan Xiaoxiang Chicken subjected to preslaughter transport stress.

\begin{tabular}{|c|c|c|c|c|c|}
\hline Items & Control group & T $3 \mathbf{h}$ & T $3 \mathrm{~h}+600 \mathrm{mg}$ GAA & T $3 \mathrm{~h}+1200 \mathrm{mg} \mathrm{GAA}$ & $P$ value \\
\hline $\mathrm{pH}_{45 \min }$ & $6.40 \pm 0.30$ & $6.29 \pm 0.22$ & $6.34 \pm 0.13$ & $6.37 \pm 0.07$ & 0.720 \\
\hline $\mathrm{pH}_{24 \mathrm{~h}}$ & $5.88 \pm 0.06^{a}$ & $5.59 \pm 0.05^{b}$ & $5.86 \pm 0.06^{a}$ & $5.87 \pm 0.09^{a}$ & $<0.001$ \\
\hline$L^{*}$ & $51.5 \pm 1.15^{\mathrm{c}}$ & $55.2 \pm 1.61^{a}$ & $53.4 \pm 1.69^{b}$ & $52.5 \pm 1.60^{\mathrm{bc}}$ & $<0.001$ \\
\hline$a^{*}$ & $1.29 \pm 0.11$ & $1.21 \pm 0.09$ & $1.22 \pm 0.18$ & $1.25 \pm 0.13$ & 0.584 \\
\hline$b^{*}$ & $5.08 \pm 0.68$ & $5.45 \pm 0.28$ & $5.06 \pm 0.21$ & $5.09 \pm 0.33$ & 0.220 \\
\hline Drip loss (\%) & $2.26 \pm 0.21^{c}$ & $2.75 \pm 0.18^{a}$ & $2.54 \pm 0.12^{b}$ & $2.30 \pm 0.24^{c}$ & $<0.001$ \\
\hline Cooking loss (\%) & $16.6 \pm 0.73^{b}$ & $18.0 \pm 1.18^{a}$ & $17.2 \pm 0.14^{\mathrm{ab}}$ & $16.8 \pm 0.89^{b}$ & 0.011 \\
\hline Shear force $(\mathrm{N})$ & $24.1 \pm 0.86$ & $25.1 \pm 1.22$ & $25.1 \pm 0.92$ & $24.3 \pm 1.11$ & 0.141 \\
\hline
\end{tabular}

Results are expressed as the mean value and standard error. Means within the same row with different superscripts differ significantly ( $n=10$ per treatment, $P<0.05$ ). Control, broilers fed the basal diet without transport stress; $T$ 3h, broilers fed the basal diet and experienced a $3 \mathrm{~h}$ transport; $T 3 \mathrm{~h}+0.06 \% \mathrm{GAA}$ or $\mathrm{T} 3 \mathrm{~h}+0.12 \%$

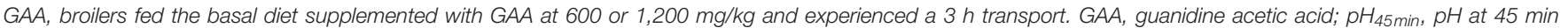
postmortem; $\mathrm{pH}_{24 h}$, $\mathrm{pH}$ at $24 \mathrm{~h}$ postmortem; L*, lightness; $a^{*}$, redness; $b^{*}$, yellowness.

TABLE 5 | Effects of dietary supplementation with GAA on muscle energy status of the pectoralis major muscle of Qiandongnan Xiaoxiang Chicken subjected to preslaughter transport stress.

\begin{tabular}{|c|c|c|c|c|c|}
\hline Items & Control group & T $3 \mathbf{~ h}$ & T $3 \mathrm{~h}+600 \mathrm{mg}$ GAA & T $3 h+1,200 \mathrm{mg}$ GAA & $P$ value \\
\hline $\mathrm{Cr}$ & $21.99 \pm 1.36^{b}$ & $19.79 \pm 1.46^{c}$ & $22.90 \pm 1.60^{a b}$ & $24.58 \pm 1.70^{\mathrm{a}}$ & 0.001 \\
\hline $\mathrm{PCr}$ & $2.24 \pm 0.15^{a b}$ & $2.10 \pm 0.17^{b}$ & $2.32 \pm 0.16^{a}$ & $2.41 \pm 1.48^{a}$ & 0.042 \\
\hline PCr: Cr & $0.10 \pm 0.01$ & $0.11 \pm 0.01$ & $0.10 \pm 0.01$ & $0.10 \pm 0.01$ & 0.731 \\
\hline ATP & $3.48 \pm 0.16^{a}$ & $3.03 \pm 0.13^{c}$ & $3.14 \pm 0.20^{b c}$ & $3.35 \pm 0.17^{a b}$ & 0.002 \\
\hline ADP & $0.90 \pm 0.03^{b}$ & $1.04 \pm 0.09^{a}$ & $0.97 \pm 0.06^{a b}$ & $0.94 \pm 0.01^{b}$ & 0.009 \\
\hline AMP & $0.32 \pm 0.03^{c}$ & $0.42 \pm 0.03^{a}$ & $0.38 \pm 0.02^{a b}$ & $0.35 \pm 0.02^{b c}$ & 0.001 \\
\hline AMP: ATP & $0.09 \pm 0.01^{b}$ & $0.14 \pm 0.02^{a}$ & $0.12 \pm 0.01^{a}$ & $0.10 \pm 0.01^{b}$ & $<0.001$ \\
\hline
\end{tabular}

Results are expressed as the mean value and standard error. Means within the same row with different superscripts differ significantly ( $n=10$ per treatment, $P<0.05$ ) Control, broilers fed the basal diet without transport stress; T3h, broilers fed the basal diet and experienced a $3 \mathrm{~h}$ transport; T3h + 0.06\% GAA or T3h + 0.12\% GAA, broilers fed the basal diet supplemented with GAA at 600 or 1,200 mg/kg and experienced a 3 h transport. GAA, guanidine acetic acid; Cr, creatine; PCr, phosphocreatine; ATP, adenosine triphosphate; ADP, adenosine diphosphate; AMP, adenosine monophosphate. 
in Figure 2. Three-hour pre-slaughter transport stress resulted in lower glycogen contents and higher lactic acid $(P<0.05$, Figures 2A,B), combined with higher glycolytic potential of PM muscle $(P<0.05$, Figure $2 \mathrm{C})$ in comparison with those of the control group. The content of lactic acid was decreased followed by $600 \mathrm{mg} / \mathrm{kg}$ GAA supplementation $(P<0.05)$; however, no differences were observed for glycogen content or glycolytic potential by $600 \mathrm{mg} / \mathrm{kg}$ GAA supplementation $(P>0.05)$. Compared with the 3 -h pre-slaughter transport, however, $1,200 \mathrm{mg} / \mathrm{kg}$ GAA addition significantly elevated the glycogen content $(P<0.05)$ and markedly decreased glycolytic potential and the concentration of lactic acid $(P<0.05)$. Moreover, the content of lactic acid of broilers supplemented with $1,200 \mathrm{mg} / \mathrm{kg}$ GAA was lower than those fed with $600 \mathrm{mg} / \mathrm{kg}$ GAA $(P<0.05)$, but there were no differences in glycogen content or glycolytic potential between these two groups $(P>0.05)$. Additionally, no differences were observed for glycogen, lactic acid, or glycolytic potential between the 1,200-mg/kg GAA group and the control group $(P>0.05)$.

\section{Activities of Glycolytic Key Enzymes}

Data on the effects of transport stress on activities of glycolytic key enzymes are shown in Figure 3. Three-hour pre-slaughter transport stress increased the activities of $\mathrm{PK}$ and $\mathrm{HK}$ (Figures $\mathbf{3 A}, \mathbf{B}$ ), as well as the activity of 2,6-PFK $(P<0.05$, Figure 3C). The activities of $\mathrm{PK}, \mathrm{HK}$, and 2,6-PFK were not significantly influenced by the $600-\mathrm{mg} / \mathrm{kg}$ GAA treatment compared to those treated with 3 -h transport stress $(P>0.05)$. In contrast, compared with the 3 -h transport stress group, the activities of PK, HK, and 2,6-PFK were all dramatically decreased by $1,200 \mathrm{mg} / \mathrm{kg}$ GAA supplementation $(P<0.05)$. Furthermore, compared to the control group, there were no differences in the activities of $\mathrm{PK}, \mathrm{HK}$, or 2,6-PFK of broilers supplemented with $1,200 \mathrm{mg} / \mathrm{kg} \mathrm{GAA}(P>0.05)$.

\section{Related mRNA Expressions and Protein Abundances in the AMPK Signaling Pathway}

The mRNA expressions and related protein abundances are shown in Figure 4. Three-hour pre-slaughter transport stress resulted in a significant elevation of mRNA expressions of LKB1 and AMPK $\alpha 2(P<0.05$, Figures 4A,B $)$, except for the mRNA expression of AMPK $\alpha 1(P>0.05$, Figure 4B). Meanwhile, protein abundances of LKB1 phosphorylation and AMPK $\alpha$ phosphorylation were both increased by 3 - $h$ transport stress $(P<0.05$, Figures $4 \mathrm{D}, \mathbf{E})$. On the contrary, compared to those treated by $3-\mathrm{h}$ transport stress, the upregulated mRNA expressions of LKB1 and AMPK $\alpha 2$, combined with the increased protein abundances of LKB1 and AMPK $\alpha$, were all reversed by $1,200 \mathrm{mg} / \mathrm{kg}$ GAA supplementation $(P<0.05)$.

\section{DISCUSSION}

Several published studies have indicated that GAA supplementation could effectively increase creatine storage in tissues and accordingly positively affected the growth performance, breast meat yield, and status of energy metabolism when GAA was supplemented with a dosage not higher than 600-800 mg GAA per kg feed for chicken (Michiels et al., 2012; Mousavi et al., 2013; Ostojic, 2015). Surprisingly, in our study, there were no differences in ADG, ADFI, or F/G of broilers supplemented with 600 or $1,200 \mathrm{mg} / \mathrm{kg}$ GAA, which was probably associated with the shorter experimental period (14 days before pre-slaughter transport). Similarly, Zhang et al. (2019) suggested that dietary supplemented with GAA prior to pre-slaughter for 14 days at a dosage of both 600 and $1,200 \mathrm{mg} / \mathrm{kg}$ did not affect ADG, ADFI, or feed efficiency of broilers. Moreover, a previous study conducted by Tossenberger et al. (2016) also demonstrated that 0.6\% GAA supplementation did not affect the growth performance of broilers.

The plasma parameters such as glucose and corticosterone were considered to be a biochemical index in response to preslaughter transport stress (Zhang et al., 2009; Voslarova et al., 2011). In our present study, 3-h pre-slaughter transport stress decreased the concentration of glucose in plasma, accompanied by an increase of corticosterone contents when compared with the control group, indicating that a stress occurred in response to 3 -h pre-slaughter transport stress. Consistent with our results, Zhang et al. (2019) suggested that 3-h transport stress exhibited higher plasma corticosterone concentration and lower plasma glucose concentration than the control group (0.5-h transport stress). However, compared with those exposed to 3-h pre-slaughter transport, dietary supplemented with $1,200 \mathrm{mg} / \mathrm{kg}$ GAA resulted in a decrease in the concentration of corticosterone, demonstrating that GAA addition could contribute to alleviating the negative effects induced by the $3-\mathrm{h}$ pre-slaughter transport.

Pre-slaughter transport causes an acute response to broilers, resulting in an inferior meat. In our present study, 3-h transport stress decreased $\mathrm{pH}_{24 \mathrm{~h}}$ values of broilers when compared with those in the control group. It was reported that the energy was generated from anaerobic glycolysis to maintain the metabolic activity of muscle cells during transport stress, resulting in the lactate and $\mathrm{H}^{+}$accumulation, then followed by a lower $\mathrm{pH}$ (Xing et al., 2016). Moreover, the accumulation of lactate and protons from rapid anaerobic glycolysis induced by transport stress cannot be timely removed by postmortem meat, which may explain why $\mathrm{pH}$ at $24 \mathrm{~h}$ postmortem in the breast of 3-h transport broilers were still lower (Wang et al., 2017). In contrast, the drip loss, cooking loss, and L* value were all increased by 3 -h transport stress. Similarly, Xing et al. (2016) demonstrated that the meat quality of broilers subjected to transport stress had higher drip loss, cooking loss, and L* value. Besides, Wang et al. (2017) also suggested that 3 -h transport stress increased the $\mathrm{L}^{*}$ value and drip loss of breast muscle at $24 \mathrm{~h}$ postmortem. Interestingly, in our present study, the broilers fed with both $600 \mathrm{mg} / \mathrm{kg} \mathrm{GAA}$ and $1,200 \mathrm{mg} / \mathrm{kg}$ GAA for two weeks before slaughtering had a lower drip loss and $\mathrm{L}^{*}$ value, combined with a higher value of $\mathrm{pH}_{24 \mathrm{~h}}$ in comparison with those subjected to 3 -h transport stress. It was reported that GAA supplementation before slaughtering could enhance the contents of available energy sources such as $\mathrm{PCr}$ and ATP, which contributes to delaying the conversion of glycogen to lactic acid and consequently maintains a $\mathrm{pH}$ value postmortem. 
A

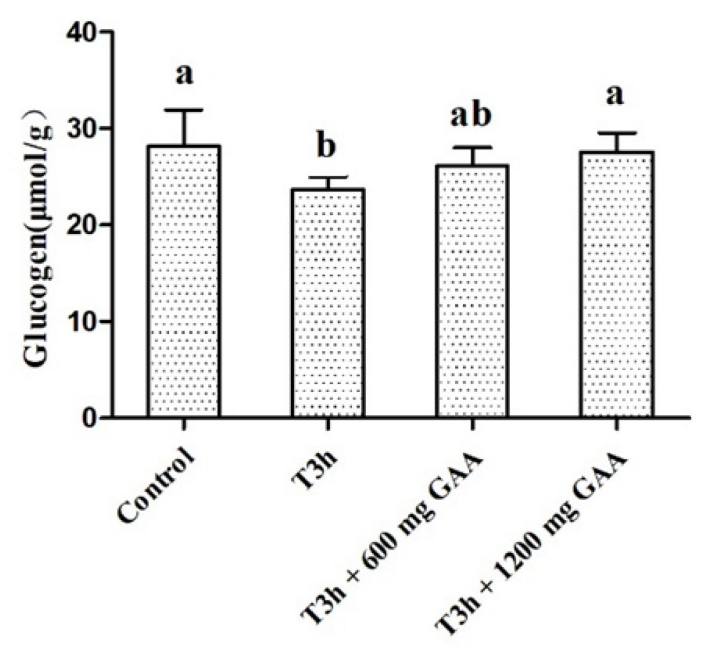

C

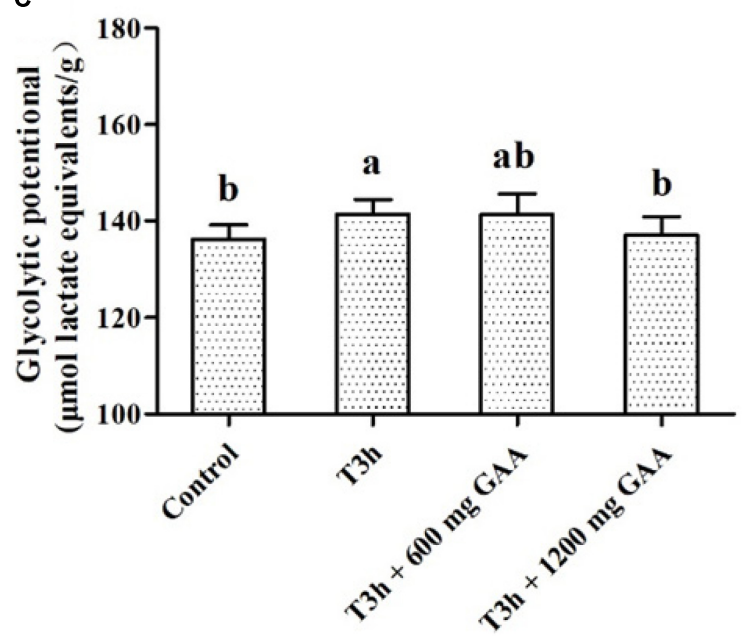

B

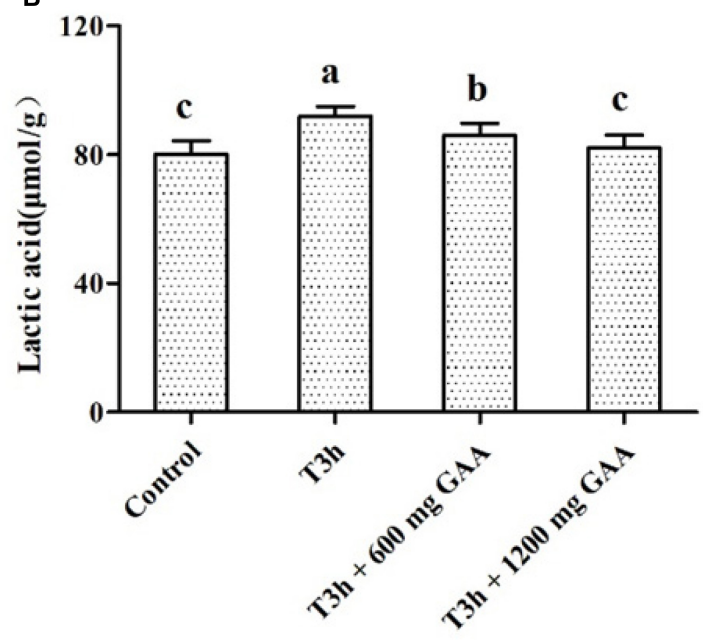

FIGURE 2 | Effects of dietary GAA supplementation on concentrations of glycogen (A), lactic acid (B), and glycolytic potential (C) in pectoralis major muscle of Qiandongnan Xiaoxiang Chicken experienced transport stress ( $n=10$ per treatment). Results are expressed as the mean value and standard error. Means within the same row with different superscripts differ significantly ( $n=10$ per treatment, $P<0.05$ ). Control, broilers fed the basal diet without transport stress; T3h, broilers fed the basal diet and experienced a $3 \mathrm{~h}$ transport; T3h + 0.06\% GAA or T3h + 0.12\% GAA, broilers fed the basal diet supplemented with GAA at 600 or 1,200 mg/kg and experienced a $3 \mathrm{~h}$ transport. GAA, guanidine acetic acid; glycolytic potential $=2 \times$ [glycogen] + [lactic acid].

Accordingly, the higher $\mathrm{pH}$ value reduced muscle protein denaturation and increased muscle water holding capacity and meat tenderness, thus improving meat quality (Huff-Lonergan and Lonergan, 2005). Consistent with our results, Zhang et al. (2019) suggested that dietary addition of $1,200 \mathrm{mg} / \mathrm{kg}$ GAA reduced drip loss compared to 3 -h pre-slaughter transport stress, which indicated that GAA supplementation prior to slaughtering could be an effective way to improve the meat quality of broilers subjected to transport stress.

It has been demonstrated that a lower ATP content and/or a higher AMP/ATP ratio in muscle were observed in broilers at the stage of pre-slaughter transport or heat stress (McKee and Sams, 1997; Savenije et al., 2002; Zhang et al., 2017). Similarly, our current study observed that 3-h transport stress decreased the contents of ATP, $\mathrm{Cr}$, and $\mathrm{PCr}$ in muscle and increased AMP and the ratio of AMP:ATP, indicating that 3-h transport stress accelerated muscle ATP exhaust accompanied by the activation of the $\mathrm{Cr}$ and phosphocreatine system. The primary physiological function of $\mathrm{Cr}$ is involved in the regulation of energy metabolism of cells, particularly muscle cells, through the $\mathrm{Cr}$ and phosphocreatine system (Michiels et al., 2012). The $\mathrm{Cr}$ and phosphocreatine system is described as a spatial energy buffer because it acts as an energy transport system that carries high-energy phosphates from mitochondrial production sites to energy utilization sites (Brosnan and Brosnan, 2007). In addition, it is a temporal energy buffer because it maintains energy homeostasis by buffering ADP and ATP ratios in order to store and mobilize energy when required on short notice, especially in muscle cells (Lemme et al., 2007). It has been demonstrated that supplemental GAA, a natural precursor of 

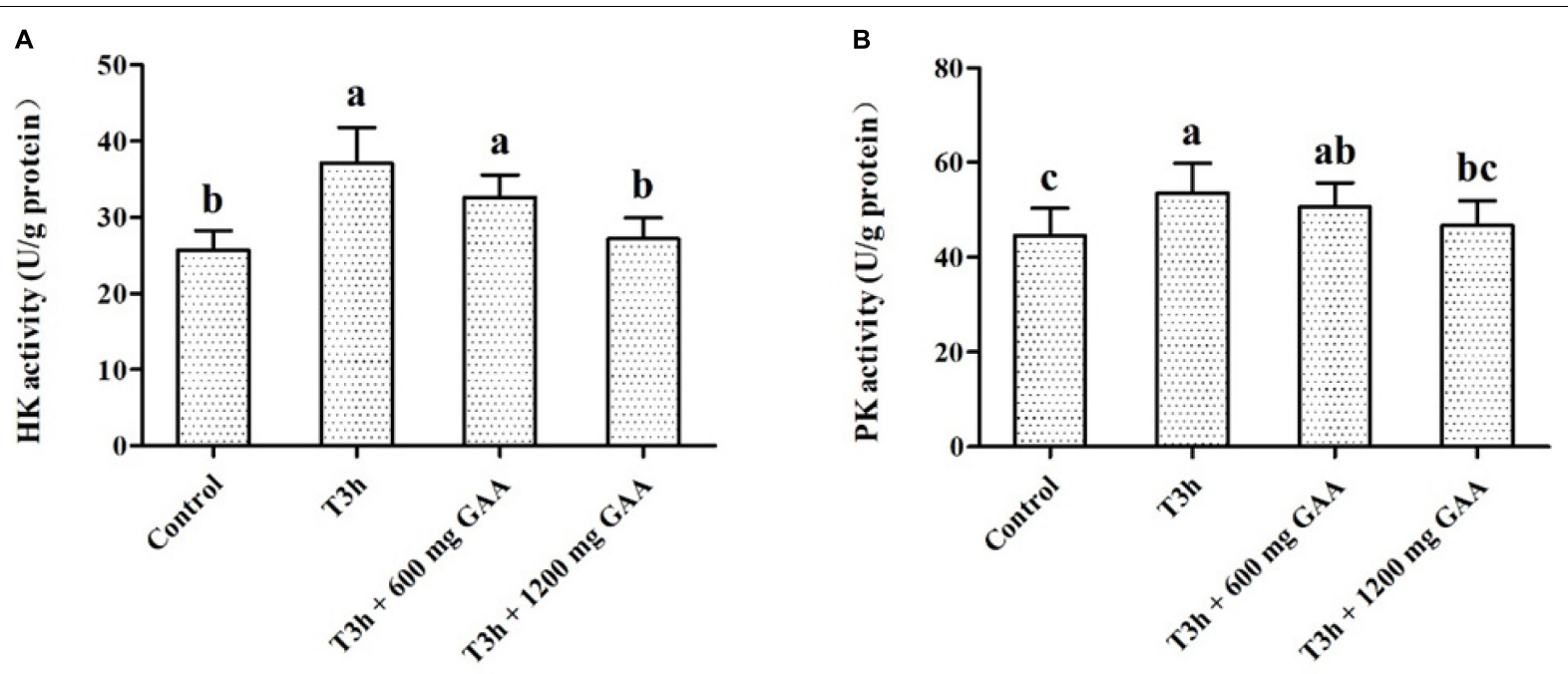

C

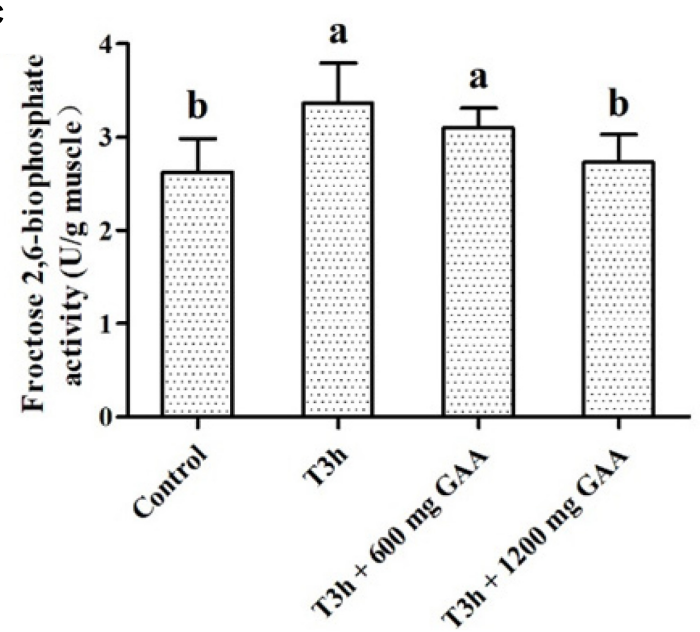

FIGURE 3 | Effects of dietary GAA supplementation on activities of HK (A), PK (B), and Fructose 2,6-niophosphate (C) in pectoralis major muscle of Qiandongnan Xiaoxiang Chicken experienced transport stress ( $n=10$ per treatment). Results are expressed as the mean value and standard error. Means within the same row with different superscripts differ significantly ( $n=10$ per treatment, $P<0.05)$. Control, broilers fed the basal diet without transport stress; T3h, broilers fed the basal diet and experienced a $3 \mathrm{~h}$ transport; T3h $+0.06 \%$ GAA or T3h $+0.12 \%$ GAA, broilers fed the basal diet supplemented with GAA at 600 or 1,200 mg/kg and experienced a $3 \mathrm{~h}$ transport. GAA, guanidine acetic acid; HK, hexokinase; PK, pyruvate kinase.

Cr, serves as an efficient $\mathrm{Cr}$ source improving the muscle energy metabolism (Lemme et al., 2007). In our study, dietary supplementation GAA at a dosage of 600 or $1,200 \mathrm{mg} / \mathrm{kg} \mathrm{GAA}$ increased the concentration of $\mathrm{Cr}$ and $\mathrm{PCr}$ in muscle when compared with the 3-h transport group. Similar with this, Michiels et al. (2012) demonstrated that GAA supplementation enhanced the contents of $\mathrm{Cr}$ and $\mathrm{PCr}$ in muscle, indicating that GAA was an efficient $\mathrm{Cr}$ source to improve energy store in the forms of $\mathrm{Cr}$ and $\mathrm{PCr}$.

It has been demonstrated that pre-slaughter stress exacerbated skeletal muscle energy consumption, evidenced by decreasing muscle ATP depletion and accelerating glycolysis metabolism, which resulted in a decreased concentration of glycogen and an elevation of lactic acid (Yue et al., 2010; Zhang et al., 2017). Similar with the results of Zhang et al. (2019), in our present study, it showed that pre-slaughter transport stress increased the concentration of lactic acid and glycolytic potential of muscle, indicating that muscle cells switch from oxidative phosphorylation to glycolysis to produce enough ATP for increased muscle energy demands in response to the limited oxygen during pre-slaughter stress and anaerobic glycolysis then became the predominant energy source for the muscle ATP supply. It has been shown that HK, PK, and LDH are the rate-limiting enzymes involved in the glycolysis pathway, which 


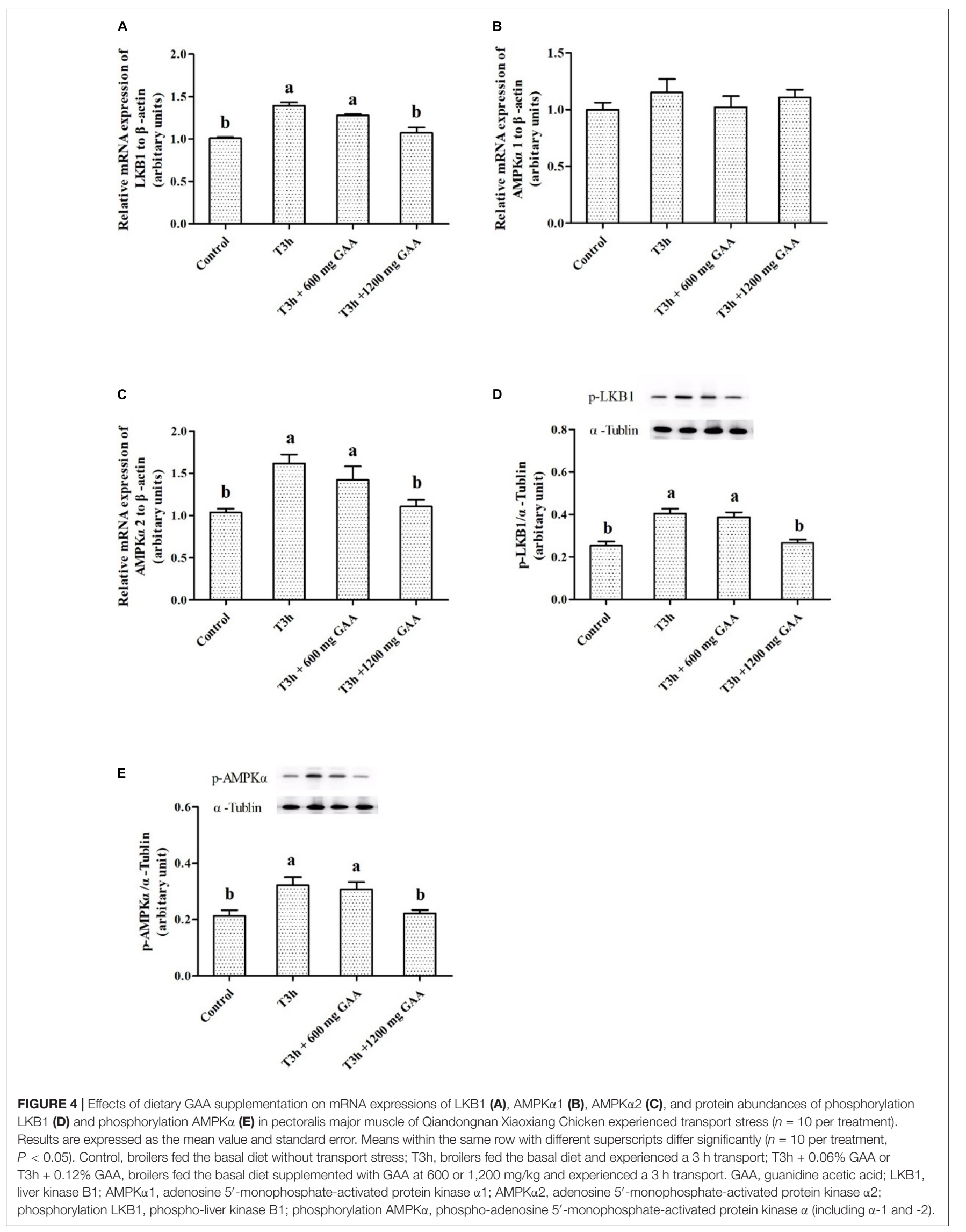


are responsible for converting glucose to glucose-6-phosphate, phosphoenolpyruvate to pyruvic acid, and pyruvic acid to lactic acid, respectively (Liu et al., 2015; Wang et al., 2017). In the present study, 3-h pre-slaughter transport stress elevated the activities of $\mathrm{PK}, \mathrm{HK}$, and $\mathrm{LDH}$ of breast, indicating that glycolysis may be triggered during 3-h pre-slaughter transport stress. However, $1,200 \mathrm{mg} / \mathrm{kg}$ GAA supplementation increased the concentration of glycogen and decreased lactic acid, glycolytic potential and the activities of $\mathrm{PK}, \mathrm{HK}$, and $\mathrm{LDH}$ of breast compared to 3-h transport stress, indicating that the rate of glycolysis reaction was downregulated because of GAA supplementation. Moreover, compared to 3-h transport stress, the increased $\mathrm{Cr}$ and $\mathrm{PCr}$ in muscle were observed by GAA supplementation, indicating that GAA supplementation may be beneficial for delaying rapid muscle anaerobic glycolysis induced by transport stress.

AMPK, which is mainly recognized as an important regulator of mitochondrial biogenesis in response to energy deprivation, is switched on by an increase in the AMP/ATP ratio via the phosphorylation of the $\alpha$ subunit at the Thr ${ }^{172}$ site by LKB1 (Du et al., 2005). AMPK is activated by stresses that deplete cellular ATP, when it acts to restore energy homeostasis by switching on catabolic pathways that generate ATP through accelerating the glycolysis process of muscle (Graeme and Hardie, 2014). However, a previous study in AMPK knockout mice demonstrated that postmortem glycolysis was inhibited (Shen et al., 2008), which suggested that AMPK played an important role in the postmortem glycolysis process in lack of oxygen. Moreover, AMPK is a heterotrimeric complex comprising $\alpha$, $\beta$, and $\gamma$ subunits, in which the $\alpha$ subunit is essential for the activation of AMPK signaling (Du et al., 2005; Graeme and Hardie, 2014). The $\alpha$ subunit of AMPK has two isoforms, $\alpha 1$ and $\alpha 2$. It was demonstrated that AMPK $\alpha 2$ but not AMPK $\alpha 1$ knockoff abolished the activity of AMPK in postmortem muscle. Besides, AMPK $\alpha 2$ knockoff reduced postmortem $\mathrm{pH}$ decline and the generation of lactate, while AMPK $\alpha 1$ knockoff had no significant effect, which suggested that the AMPK $\alpha 2$ catalytic subunit mainly regulates postmortem glycolysis in muscle (Liang et al., 2013). In our present study, it was observed that both LKB1 mRNA expression level and LKB1 protein abundances, combined with the phosphorylation abundance of $\mathrm{AMPK} \alpha$ at $\mathrm{Thr}^{172}$, were all increased by 3 -h transport stress, indicating that the energy metabolism of muscle under preslaughter transport stress was mediated by AMPK signaling. Similarly, it has been suggested that pre-slaughter transport stress accelerated the process of glycolysis, recognized by increasing an accumulation of lactate and subsequently an activation of the AMPK signaling pathway (Xing et al., 2016). Meanwhile, our study also indicated that AMPK $\alpha 2$ but not AMPK $\alpha 1$ was

\section{REFERENCES}

Brosnan, J. T., and Brosnan, M. E. (2007). Creatine: endogenous metabolite, dietary, and therapeutic supplement. J. Annu. Rev. Nutr. 27, 241-261. doi: 10.1146/annurev.nutr.27.061406.093621

Degroot, A. A. (2015). Efficacy of Dietary Guanidinoacetic Acid in Broiler Chicks. Master Degree. Urbana IL: University of Illinois at Urbana-Champaign. elevated in response to 3 -h transport stress. Nevertheless, dietary GAA supplementation downregulated the mRNA expressions of muscle LKB1 and AMPK $\alpha 2$, and the protein expression of LKB1 and the phosphorylation abundance of AMPK $\alpha \mathrm{Thr}^{172}$, suggesting that dietary GAA addition may be an effective way in delaying anaerobic glycolysis via inhibiting the transport stressinduced activation of the AMPK pathway.

\section{DATA AVAILABILITY STATEMENT}

The original contributions presented in the study are included in the article/supplementary material, further inquiries can be directed to the corresponding author/s.

\section{ETHICS STATEMENT}

The animal study was reviewed and approved by Institutional Animal Care and Use Committee of Zunyi Normal College.

\section{AUTHOR CONTRIBUTIONS}

$\mathrm{RL}$, JL, and NL participated in the animal trial and sample analysis together with $\mathrm{BZ}$. BZ performed the data analysis and wrote the manuscript. $\mathrm{ZH}, \mathrm{PS}, \mathrm{MH}$, and $\mathrm{YX}$ assisted in conducting the experimental analysis. BZ and ZS designed and supervised the study and revised the manuscript. All authors contributed to the article and approved the submitted version.

\section{FUNDING}

This work was financially supported by National Natural Science Foundation of China (No. 31760674), the Basic Project of Guizhou Provincial Natural Science Foundation [Qian Kehe (2017)1205], Zunyi 15851 Talent Project (2050020213\#), Zunyi City-School Joint Fund [Zunshi Kehe (2018) No. 08], the Rural Industrial Revolution Project of Guizhou Province (Zunshi he Rural Industry 201905), and Zunshi Chi Shuihe Fund [Zunshi CSHKJ(2019)-01].

\section{ACKNOWLEDGMENTS}

We are grateful to Guizhou Rongjiang Shannong Development Co., Ltd. (China) for providing the Qiandongnan Xiaoxiang Chickens.

Desai, M. A., Jackson, V., Zhai, W., Suman, S. P., Nair, M. N., Beach, C. M., et al. (2016). Proteome basis of pale, soft, and exudative-like (PSE-like) broiler breast (Pectoralis major) meat. Poult. Sci. 95, 2696-2706. doi: 10.3382/ps/pew213

Dilger, R. N., Bryant-Angeloni, K., Payne, R. L., Lemme, A., and Parsons, C. M. (2013). Dietary guanidino acetic acid is an efficacious replacement for arginine for young chicks. Poult. Sci. 92, 171-177. doi: 10.3382/ps.201202425 
Du, M., Shen, Q. W., and Zhu, M. J. (2005). Role of beta-adrenoceptor signaling and AMP-activated protein kinase in glycolysis of postmortem skeletal muscle. J. Agric. Food Chem. 53, 3235-3239. doi: 10.1021/jf047913n

Graeme, G. J., and Hardie, D. G. (2014). AMPK: a cellular energy sensor primarily regulated by AMP. Biochem. Soc. Trans. 42, 71-75.

Hambrecht, E., Eissen, J. J., Newman, D. J., Smits, C. H., Verstegen, M. W., and den Hartog, L. A. (2005). Preslaughter handling effects on pork quality and glycolytic potential in two muscles differing in fiber type composition. J. Anim. Sci. 83, 900-907. doi: 10.2527/2005.834900x

Hardie, D. G. (2011). Energy sensing by the AMP-activated protein kinase and its effects on muscle metabolism. Proc. Nutr. Soc. 70, 92-99. doi: 10.1017/ S0029665110003915

Huang, J., Yang, J., Huang, M., Zhu, Z., Sun, X., Zhang, B., et al. (2018). Effect of pre-slaughter shackling and wing flapping on plasma parameters, postmortem metabolism, AMPK, and meat quality of broilers. Poult. Sci. 97, 1841-1847. doi: $10.3382 / \mathrm{ps} / \mathrm{pey} 019$

Huff-Lonergan, E., and Lonergan, S. M. (2005). Mechanisms of water-holding capacity of meat: the role of postmortem biochemical and structural changes. Meat Sci. 71, 194-204. doi: 10.1016/j.meatsci.2005.04.022

Lemme, A., Ringel, J., Sterk, A., and Young, J. F. (2007). "Supplemental guanidino acetic acid affects energy metabolism of broilers," in World Poultry Science Association, Proceedings of the 16th European Symposium on Poultry Nutrition, Vol. 26-30, Strasbourg, 339-342.

Li, Z., Li, X., Wang, Z., Shen, Q., and Zhang, D. (2016). Antemortem stress regulates protein acetylation and glycolysis in postmortem muscle. Food Chem. 202, 94-98. doi: 10.1016/j.foodchem.2016.01.085

Liang, J., Yang, Q., Zhu, M. J., Jin, Y., and Du, M. (2013). AMP-activated protein kinase (AMPK) a2 subunit mediates glycolysis in postmortem skeletal muscle. Meat Sci. 95, 536-541. doi: 10.1016/j.meatsci.2013.05.025

Liu, Y., Li, J. L., Li, Y. J., Gao, T., Zhang, L., Gao, F., et al. (2015). Effects of dietary supplementation of guanidinoacetic acid and combination of guanidinoacetic acid and betaine on postmortem glycolysis and meat quality of finishing pigs. Anim. Feed Sci. Technol. 205, 82-89. doi: 10.1016/j.anifeedsci.2015.03.010

Livak, K., and Schmittgen, T. (2000). Analysis of relative gene expression data using real-time quantitative PCR and the $2^{-\Delta \Delta C t}$ Method. Methods 25, 402-408. doi: $10.5897 / \mathrm{AJB} 11.4117$

McBreairty, L. E., Robinson, J. L., Furlong, K. R., Brunton, J. A., and Bertolo, R. F. (2015). Guanidinoacetate is more effective than creatine at enhancing tissue creatine stores while consequently limiting methionine availability in Yucatan miniature pigs. PLoS One 10:e0131563. doi: 10.1371/journal.pone.0131563

McKee, S. R., and Sams, A. (1997). The effect of seasonal heat stress on rigor development and the incidence of pale, exudative turkey meat. Poult. Sci. 76, 1616-1620. doi: 10.1093/ps/76.11.1616

Michiels, J., Maertens, L., Buyse, J., Lemme, A., Rademacher, M., Dierick, N. A., et al. (2012). Supplementation of guanidinoacetic acid to broiler diets: effects on performance, carcass characteristics, meat quality, and energy metabolism. Poult. Sci. 91, 402-412. doi: 10.3382/ps.2011-01585

Monin, G., and Sellier, P. (1985). Pork of low technological quality with a normal rate of muscle $\mathrm{pH}$ fall in the immediate post-mortem period: the case of the Hampshire breed. Meat Sci. 13, 49-63. doi: 10.1016/S0309-1740(85)80004-8

Mousavi, S. N., Afsar, A., and Lotfollahian, H. (2013). Effects of guanidinoacetic acid supplementation to broiler diets with varying energy contents. J. Appl. Poult. Res. 22, 47-54. doi: 10.3382/japr.2012-00575

Ostojic, S. M. (2015). Guanidinoacetic acid as a performance-enhancing agent. Amino Acids 48, 1867-1875. doi: 10.1007/s00726-015-2106-y

Ostojic, S. M., Niess, B., Stojanovic, M., and Obrenovic, M. (2013). Creatine metabolism and safety profiles after six-week oral guanidinoacetic acid administration in healthy humans. Int. J. Med. Sci. 10, 141-147. doi: 10.7150/ ijms.5125

Savenije, B., Lambooij, E., Gerritzen, M., Venema, K., and Korf, J. (2002). Effects of feed deprivation and transport on preslaughter blood metabolites, early postmortem muscle metabolites, and meat quality. Poult. Sci. 81, 699-708. doi: $10.1093 / \mathrm{ps} / 81.5 .699$
Schwartzkopf-Genswein, K. S., Faucitano, L., Dadgar, S., Shand, P., Gonzalez, L. A., and Crowe, T. G. (2012). Road transport of cattle, swine and poultry in North America and its impact on animal welfare, carcass and meat quality: a review. Meat Sci. 92, 227-243. doi: 10.1016/j.meatsci.2012.04.010

Shen, Q. W., Gerrard, D. E., and Du, M. (2008). Compound C, an inhibitor of AMP-activated protein kinase, inhibits glycolysis in mouse longissimus dorsi postmortem. Meat Sci. 78, 323-330. doi: 10.1016/j.meatsci.2007.06.023

Speer, N. C., Slack, G., and Troyer, E. (2001). Economic factors associated with livestock transportation. J. Anim. Sci. 79(Suppl__E), E166-E170. doi: 10.2527/ jas2001.79E-SupplE166x

Tossenberger, J., Rademacher, M., Németh, K., Halas, V., and Lemme, A. J. P. S. (2016). Digestibility and metabolism of dietary guanidino acetic acid fed to broilers. Poult. Sci. 95, 2058-2067. doi: 10.3382/ps/pew083

Voslarova, E., Chloupek, P., Vosmerova, P., Chloupek, J., Bedanova, I., and Vecerek, V. (2011). Time course changes in selected biochemical indices of broilers in response to pretransport handling. Poult. Sci. 90, 2144-2152. doi: 10.3382/ps.2011-01473

Wang, L. S., Shi, B. M., Shan, A. S., and Zhang, Y. Y. (2012). Effects of guanidinoacetic acid on growth performance, meat quality and antioxidation in growing-finishing pigs. J. Anim. Vet. Adv. 11, 631-636. doi: 10.3923/javaa.2012 631.636

Wang, X., Li, J., Cong, J., Chen, X., Zhu, X., Zhang, L., et al. (2017). Preslaughter transport effect on broiler meat quality and postmortem glycolysis metabolism of muscles with different fiber types. J. Agric. Food Chem. 65, 10310-10316. doi: $10.1021 /$ acs.jafc.7b04193

Xing, T., Xu, X., Jiang, N., and Deng, S. (2016). Effect of transportation and preslaughter water shower spray with resting on AMP-activated protein kinase, glycolysis and meat quality of broilers during summer. Anim. Sci. J. 87, 299-307. doi: 10.1111/asj.12426

Yue, H. Y., Zhang, L., Wu, S. G., Xu, L., Zhang, H. J., and Qi, G. H. (2010). Effects of transport stress on blood metabolism, glycolytic potential, and meat quality in meat-type yellow-feathered chickens. Poult. Sci. 89, 413-419. doi: 10.3382/ps.2009-00550

Zhang, L., Li, J. L., Gao, T., Lin, M., Wang, X. F., Zhu, X. D., et al. (2014). Effects of dietary supplementation with creatine monohydrate during the finishing period on growth performance, carcass traits, meat quality and muscle glycolytic potential of broilers subjected to transport stress. Animal 8, 1955-1962. doi: 10.1017/S1751731114001906

Zhang, L., Li, J. L., Wang, X. F., Zhu, X. D., Gao, F., and Zhou, G. H. (2019). Attenuating effects of guanidinoacetic acid on preslaughter transport-induced muscle energy expenditure and rapid glycolysis of broilers. Poult. Sci. 98, 3223-3232. doi: 10.3382/ps/pez052

Zhang, L., Wang, X., Li, J., Zhu, X., Gao, F., and Zhou, G. (2017). Creatine monohydrate enhances energy status and reduces glycolysis via inhibition of AMPK pathway in pectoralis major muscle of transportstressed broilers. J. Agric. Food Chem. 65, 6991-6999. doi: 10.1021/acs.jafc.7b 02740

Zhang, L., Yue, H. Y., Zhang, H. J., Xu, L., Wu, S. G., Yan, H. J., et al. (2009). Transport stress in broilers: I. Blood metabolism, glycolytic potential, and meat quality. Poult. Sci. 88, 2033-2041. doi: 10.3382/ps.200900128

Conflict of Interest: The authors declare that the research was conducted in the absence of any commercial or financial relationships that could be construed as a potential conflict of interest.

Copyright (C) 2021 Zhang, Liu, He, Song, Hao, Xie, Li, Liu and Sun. This is an open-access article distributed under the terms of the Creative Commons Attribution License (CC BY). The use, distribution or reproduction in other forums is permitted, provided the original author(s) and the copyright owner(s) are credited and that the original publication in this journal is cited, in accordance with accepted academic practice. No use, distribution or reproduction is permitted which does not comply with these terms. 